\title{
Fault Diagnosis Models for Electric Locomotive Systems Based on Fuzzy Reasoning Spiking Neural P Systems
}

\author{
Tao Wang ${ }^{1}$, Gexiang Zhang ${ }^{1}$, and Mario J. Pérez-Jiménez ${ }^{2(\bowtie)}$ \\ 1 School of Electrical Engineering, Southwest Jiaotong University, \\ Chengdu 610031, People's Republic of China \\ wangtaocdu@gmail.com, zhgxdylan@126.com \\ 2 Department of Computer Science and Artificial Intelligence, Research Group \\ on Natural Computing, University of Sevilla, 41012 Sevilla, Spain \\ marper@us.es
}

\begin{abstract}
This paper discusses the application of fuzzy reasoning spiking neural $\mathrm{P}$ systems with real numbers (rFRSN $\mathrm{P}$ systems) to fault diagnosis of electric locomotive systems. Relationships among breakdown signals and faulty sections in subsystems of electric locomotive systems are described in the form of fuzzy production rules firstly and then fault diagnosis models based on rFRSN P systems for these subsystems are built according to these rules. Fuzzy production rules for diagnosing electric locomotive systems are abstracted from the fault diagnosis analysis of the subsystems and the causality among faulty sections, faulty subsystems and electric locomotive systems. Finally, a diagnosis model based on rFRSN P systems for electric locomotive systems is proposed.
\end{abstract}

Keywords: Fuzzy reasoning spiking neural P system · Fault diagnosis - Electric locomotive system - Real number · SS4 electric locomotive systems

\section{Introduction}

Spiking neural P systems (SN P systems), introduced in [2] in the framework of membrane computing, is a new class of computing devices which are inspired by the neurophysiological behavior of neurons sending electrical impulses (spikes) along axons to other neurons. Since then, SN P systems have become a hot topic in membrane computing [3]-[21], including investigations focusing on the use of SN P systems and their variants to solve engineering problems in power systems [18]-[21].

In [18], fuzzy reasoning spiking neural $\mathrm{P}$ systems with real numbers (rFRSN $\mathrm{P}$ systems) were introduced in order to capture the diagnosis knowledge representation and reasoning. The merits of rFRSN P systems lie in visually describing fuzzy production rules in a fuzzy diagnosis knowledge systems, where they effectively model the relationships among breakdown signals and faulty sections and represent and handle fuzzy knowledge/information. This paper discusses the

(c) Springer International Publishing Switzerland 2014

M. Gheorghe et al. (Eds.): CMC 2014, LNCS 8961, pp. 385-395, 2014.

DOI: $10.1007 / 978-3-319-14370-5 \_24$ 
application of rFRSN P systems to the fault diagnosis of the Shaoshan4 (SS4) electric locomotive systems (always indicate SS4 electric locomotive systems).

Electric locomotive systems are composed of several subsystems with different functions; meanwhile, these subsystems consist of numerous sections. Thus, a locomotive system can be viewed as a hierarchical tree structure of sections and subsystems [22,23]. To build fault diagnosis models based on rFRSN P systems for different subsystems, relationships among breakdown signals and faulty sections in subsystems are abstracted and described in the form of fuzzy production rules firstly. Then, fault diagnosis models for these subsystems are built based on these rules. Fuzzy production rules for diagnosing electric locomotive systems are derived in accordance with causality rules among faulty sections, faulty subsystems and SS4 electric locomotive systems. It is worth pointing out that rFRSN $\mathrm{P}$ systems used in this paper contain three types of rule neurons, i.e., GENERAL, $A N D$ and $O R$, while the ones in [18] only contain two types: $A N D$ and $O R$.

This paper is structured as follows. Section 2 introduces preliminary definitions and concepts utilsed in this work. The fault diagnosis models for key subsystems and electric locomotive systems are presented in Section 3. Conclusions are drawn in Section 4.

\section{Preliminaries}

In this section, we briefly review the basic concepts of rFRSN P systems [18]. Here, only the necessary prerequisites are introduced.

Definition 1: An rFRSN P system of degree $m \geq 1$ is a tuple $\Pi=\left(O, \sigma_{1}, \ldots\right.$, $\sigma_{m}$, syn, in, out), where:

(1) $O=\{a\}$ is a singleton alphabet ( $a$ is called spike);

(2) $\sigma_{1}, \ldots, \sigma_{m}$ are neurons, of the form $\sigma_{i}=\left(\theta_{i}, c_{i}, r_{i}\right), 1 \leq i \leq m$, where:

(a) $\theta_{i}$ is a real number in $[0,1]$ representing the potential value of spikes (i.e. value of electrical impulses) contained in neuron $\sigma_{i}$;

(b) $c_{i}$ is a real number in $[0,1]$ representing the fuzzy truth value corresponding to neuron $\sigma_{i}$

(c) $r_{i}$ represents a firing (spiking) rule contained in neuron $\sigma_{i}$ with the form $E / a^{\theta} \rightarrow a^{\beta}$, where $E$ is the firing condition and its form will be specified below, $\theta$ and $\beta$ are real numbers in $[0,1]$;

(3) $\operatorname{syn} \subseteq\{1,2, \ldots, m\} \times\{1,2, \ldots, m\}$ with $i \neq j$ for all $(i, j) \in$ syn $, 1 \leq i, j \leq$ $m$, is a directed graph of synapses between the linked neurons;

(4) in, out $\subseteq\{1,2, \ldots, m\}$ indicate the input neuron set and the output neuron set of $\Pi$, respectively.

In rFRSN $\mathrm{P}$ systems, each neuron associates with either a fuzzy proposition or a fuzzy production rule, and $c_{i} \in[0,1]$ is used to express a truth value of this fuzzy proposition or confidence factor $(\mathrm{CF})$ of this fuzzy production rule. Each neuron $\sigma_{i}$ contains only one firing (spiking) rule, of the form $E / a^{\theta} \rightarrow a^{\beta}$, where $E=a^{n}$ and $n$ is the number of input synapses from other neurons to the neuron. It can be applied if and only if $\sigma_{i}$ contains at least $n$ spikes, otherwise, the rule cannot be enabled until $n$ spikes are received. For neuron $\sigma_{i}$, if its firing 
rule is applied, then its pulse value $\theta_{i}$ is consumed and a new spike with value $\beta$ is produced in $\sigma_{i}$. Once the spike with value $\beta$ is emitted from $\sigma_{i}$, each neuron $\sigma_{j}$ with $(i, j) \in$ syn immediately receives this spike.

In rFRSN $\mathrm{P}$ systems, the neurons are extended to four types (proposition neurons and three kinds of rule neurons: $G E N E R A L, A N D$ and $O R$ ) and the pulse value contained in each neuron is no longer the number of spikes represented by a real value, but a real number in $[0,1]$ representing the potential value of spikes contained in neuron $\sigma_{i}$. For neuron $\sigma_{i}$, if $\theta_{i}>0$, then the neuron contains a spike with pulse value $\theta_{i}$; otherwise, it contains no spike and its pulse is 0 . For different types of neurons, their definitions and the operations for pulse values are different. We only introduce the definition of GENERAL rule neurons. Details about the other three types of neurons can be found in [18].

Definition 2: A GENERAL rule neuron is associated with a fuzzy production rule which has only one proposition in the antecedent part of the rule. Such a neuron is represented by a rectangle, as shown is Fig. 1.

A GENERAL rule neuron has only one presynaptic proposition neuron and one or more postsynaptic proposition neurons. If a $G E N E R A L$ rule neuron receives a spike from its presynaptic proposition neuron and its firing condition is satisfied, then the neuron fires and produces a new spike with the potential value $\beta=\theta * c$, where $\beta, \theta$ and $c$ are real numbers in $[0,1]$.

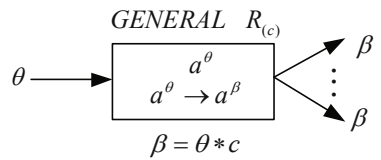

(a)

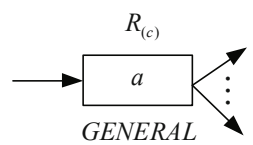

(b)

Fig. 1. A GENERAL rule neuron (a) and its simplified form (b)

\section{Fault Diagnosis Models for Electric Locomotive Systems Based on rFRSN P Systems}

In this section, fault diagnosis models based on rFRSN P systems for SS4 electric locomotive systems and their main subsystems, i.e., main circuit systems, power supply systems, traction and breaking systems, are proposed. Since an SS4 electric locomotive system can be viewed as a hierarchial tree structure of subsystems and sections shown in Fig. 2, we can build the diagnosis models from leaves to the top (that is, the root) of the tree. Thus, we firstly build the models for subsystems and then analyze these models and relationships among an electric locomotive system, its subsystems and faulty sections in these subsystems. Finally, a fault diagnosis model for SS4 electric locomotive systems is proposed.

\subsection{A Fault Diagnosis Model for the Main Circuit Systems}

Fuzzy production rules (Rules 1 to 16), describing the relationships between breakdown signals detected and candidate faulty sections, for main circuit 


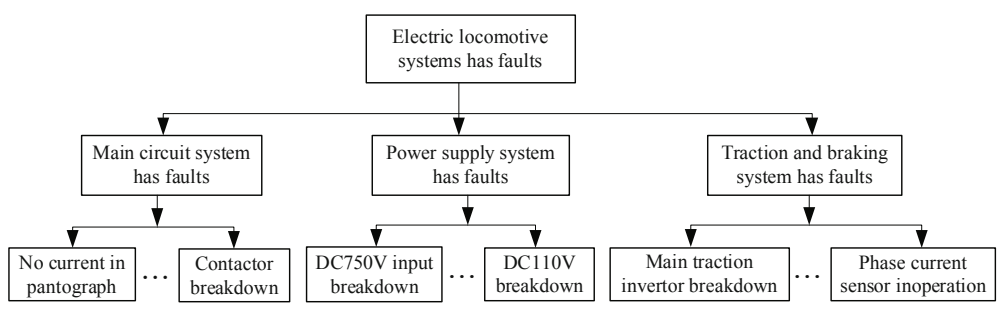

Fig. 2. A hierarchial tree structure of components in an SS4 electric locomotive system

systems of electric locomotives are described as follows, where CF represents the certainty (confidence) factor of a rule, $P_{1}, \ldots, P_{18}$ are propositions whose meanings are shown in Table 1 . According to these fuzzy production rules, a fault diagnosis model based on rFRSN $\mathrm{P}$ systems for main circuit systems $\Pi_{1}=\left(O, \sigma_{1}, \ldots, \sigma_{34}\right.$, syn, in, out $)$ is built, as shown in Fig. 3, where:

(1) $O=\{a\}$ is the singleton alphabet ( $a$ is called spike);

(2) $\sigma_{1}, \ldots, \sigma_{18}$ are proposition neurons associated with propositions $P_{1}, \ldots, P_{18}$, respectively;

(3) $\sigma_{19}, \ldots, \sigma_{28}, \sigma_{30}, \ldots, \sigma_{34}$ are $G E N E R A L$ rule neurons associated with fuzzy production rules $R_{1}, \ldots, R_{10}, R_{12}, \ldots, R_{16}$, respectively; $\sigma_{29}$ is an $O R$ rule neuron associated with fuzzy production rule $R_{11}$;

(4) $\operatorname{syn}=\{(1,19),(2,20),(3,21),(4,22),(5,23),(6,24),(7,25),(8,26),(9,27)$, $(10,28),(11,29),(12,29),(13,30),(14,31),(15,32),(16,33),(17,34),(19,13)$, $(20,13),(21,13),(22,14),(23,14),(24,14),(25,15),(26,15),(27,16),(28,16)$, $(29,17),(30,18),(30,15),(31,18),(31,15),(32,18),(33,15),(34,18)\}$;

(5) in $=\left\{\sigma_{1}, \ldots, \sigma_{12}\right\}$, out $=\left\{\sigma_{18}\right\}$.

Rule 1: IF $P_{1}$ THEN $P_{13}(\mathrm{CF}=0.95) ;$ Rule 9: IF $P_{9}$ THEN $P_{16}(\mathrm{CF}=0.95)$

Rule 2: IF $P_{2}$ THEN $P_{13}(\mathrm{CF}=0.85) ;$ Rule 10: IF $P_{10}$ THEN $P_{16}(\mathrm{CF}=0.9)$

Rule 3: IF $P_{3}$ THEN $P_{13}(\mathrm{CF}=0.9)$; Rule 11: IF $P_{11}$ OR $P_{12}$ THEN $P_{17}(\mathrm{CF}=0.9)$

Rule 4: IF $P_{4}$ THEN $P_{14}(\mathrm{CF}=0.8) ;$ Rule 12 : IF $P_{13}$ THEN $P_{15}$ AND $P_{18}(\mathrm{CF}=1.0)$ Rule 5: IF $P_{5}$ THEN $P_{14} \quad(\mathrm{CF}=0.85) ;$ Rule 13: IF $P_{14}$ THEN $P_{15}$ AND $P_{18}(\mathrm{CF}=0.9)$

Rule 6: IF $P_{6}$ THEN $P_{14}(\mathrm{CF}=0.8) ;$ Rule 14: IF $P_{15}$ THEN $P_{18}(\mathrm{CF}=0.9)$

Rule 7: IF $P_{7}$ THEN $P_{15}(\mathrm{CF}=0.95) ;$ Rule 15 : IF $P_{16}$ THEN $P_{15}(\mathrm{CF}=0.85)$

Rule 8: IF $P_{8}$ THEN $P_{15}(\mathrm{CF}=0.8) ;$ Rule 16: IF $P_{17}$ THEN $P_{18}(\mathrm{CF}=0.85)$

Table 1. Meaning of each proposition in fuzzy production rules for main circuit systems

\begin{tabular}{|l|c|c|c|}
\hline$P_{1}$ & pantograph bounce & $P_{10}$ & nonlinear resistor sparkwear \\
\hline$P_{2}$ & mechanical part damaged & $P_{11}$ & coil/main contact sparkwear \\
\hline$P_{3}$ & scratching of pantograph & $P_{12}$ & contact in poor contact \\
\hline$P_{4}$ & insulating oil damp & $P_{13}$ & no current in pantograph \\
\hline$P_{5}$ & cooling system breakdown & $P_{14}$ & traction transformer breakdown \\
\hline$P_{6}$ & transformer internal breakdown & $P_{15}$ & pulling motor inoperation \\
\hline$P_{7}$ & electrical strength reduction & $P_{16}$ & circuit breaker inoperation \\
\hline$P_{8}$ & electromotor overload & $P_{17}$ & contactor breakdown \\
\hline$P_{9}$ & isolating switch sparkwear & $P_{18}$ & main circuit breakdown \\
\hline
\end{tabular}




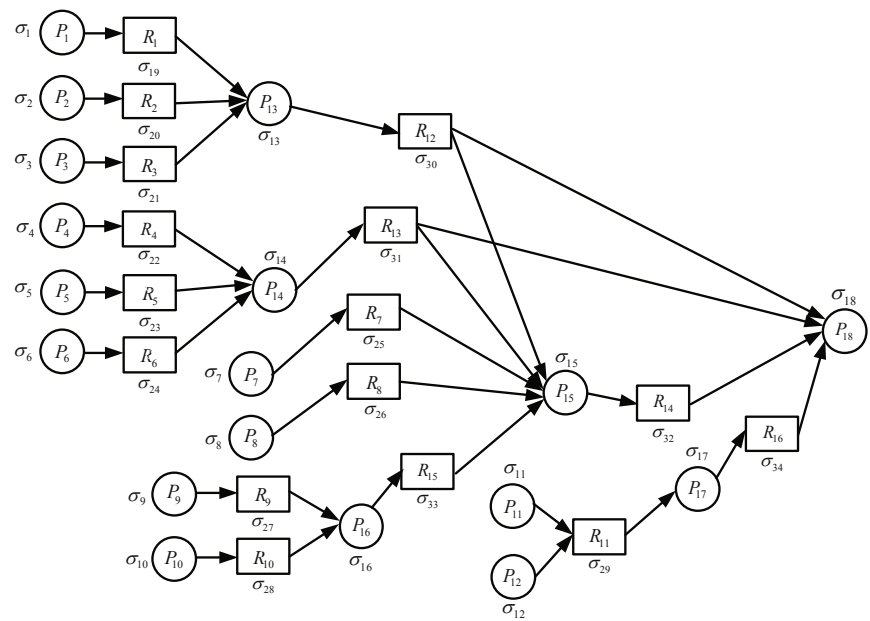

Fig. 3. A fault diagnosis model based on rFRSN P systems for the main circuit systems

\subsection{A Fault Diagnosis Model for the Power Supply Systems}

Fuzzy production rules (Rules 1 to 13), describing the relationships between breakdown signals detected and candidate faulty sections, for power supply systems of electric locomotives are described as follows, where CF represents the certainty (confidence) factor of a rule, $P_{1}, \ldots, P_{17}$ are propositions whose meanings are shown in Table 2. According to these fuzzy production rules, a fault diagnosis model based on rFRSN $\mathrm{P}$ systems for power supply systems $\Pi_{2}=\left(O, \sigma_{1}, \ldots, \sigma_{30}\right.$, syn, in, out $)$ is built, as shown in Fig. 4, where:

(1) $O=\{a\}$ is the singleton alphabet ( $a$ is called spike);

(2) $\sigma_{1}, \ldots, \sigma_{17}$ are proposition neurons associated with propositions $P_{1}, \ldots, P_{17}$, respectively;

(3) $\sigma_{18}, \ldots, \sigma_{21}, \sigma_{23}, \sigma_{24}, \sigma_{26}, \ldots, \sigma_{30}$ are $G E N E R A L$ rule neurons associated with fuzzy production rules $R_{1}, \ldots, R_{4}, R_{6}, R_{7}, R_{9}, \ldots, R_{13}$, respectively; $\sigma_{22}$ is an $O R$ rule neuron associated with fuzzy production rule $R_{5} ; \sigma_{25}$ is an $A N D$ rule neuron associated with fuzzy production rule $R_{8}$;

(4) syn $=\{(1,18),(2,19),(3,20),(4,21),(5,22),(6,23),(7,24),(8,25),(9,26)$, $(10,27),(11,22),(12,28),(13,25),(14,29),(16,30),(18,17),(19,10),(20,10)$, $(21,11),(22,12),(23,14),(23,13),(24,13),(25,15),(26,16),(27,17),(27,11)$, $(27,13),(27,14),(28,14),(28,17),(29,16),(30,17)\}$

(5) in $=\left\{\sigma_{1}, \ldots, \sigma_{9}\right\}$, out $=\left\{\sigma_{15}, \sigma_{17}\right\}$.

Rule 1: IF $P_{1}$ THEN $P_{17}(\mathrm{CF}=0.9)$

Rule 2: IF $P_{2}$ THEN $P_{10}(\mathrm{CF}=0.8)$

Rule 3: IF $P_{3}$ THEN $P_{10}(\mathrm{CF}=0.85)$

Rule 4: IF $P_{4}$ THEN $P_{11}(\mathrm{CF}=0.9)$

Rule 5: IF $P_{5}$ OR $P_{11}$ THEN $P_{12}(\mathrm{CF}=0.85)$

Rule 6: IF $P_{6}$ THEN $P_{13}$ AND $P_{14}(\mathrm{CF}=0.8)$

Rule 7: IF $P_{7}$ THEN $P_{13}(\mathrm{CF}=0.95)$

Rule 8: IF $P_{8}$ AND $P_{13}$ THEN $P_{15}(\mathrm{CF}=0.85)$

Rule 9: IF $P_{9}$ THEN $P_{16}(\mathrm{CF}=0.9)$ 
Table 2. Meaning of each proposition in fuzzy production rules for power supply systems

\begin{tabular}{|c|c|c|c|}
\hline$P_{1}$ & main traction invertor breakdown & $P_{9}$ & fan breakdown \\
\hline$P_{2}$ & current collector breakdown & $P_{10}$ & DC750V input breakdown \\
\hline$P_{3}$ & locomotive current collector breakdown & $P_{11}$ & $110 \mathrm{~V}$ DC/DC chopper inoperation \\
\hline$P_{4}$ & $110 \mathrm{~V}$ DC/DC chopper breakdown & $P_{12}$ & DC110V breakdown \\
\hline$P_{5}$ & $110 \mathrm{~V}$ accumulator breakdown & $P_{13}$ & $280 \mathrm{~V}$ DC/DC chopper inoperation \\
\hline$P_{6}$ & auxiliary inverter breakdown & $P_{14}$ & auxiliary inverter inoperation \\
\hline$P_{7}$ & $280 \mathrm{~V}$ DC/DC chopper breakdown & $P_{15}$ & DC280V breakdown \\
\hline$P_{8}$ & $280 \mathrm{~V}$ accumulator breakdown & $P_{16}$ & fan inoperation \\
\hline$P_{17}$ & \multicolumn{3}{|c|}{ main traction invertor inoperation } \\
\hline
\end{tabular}

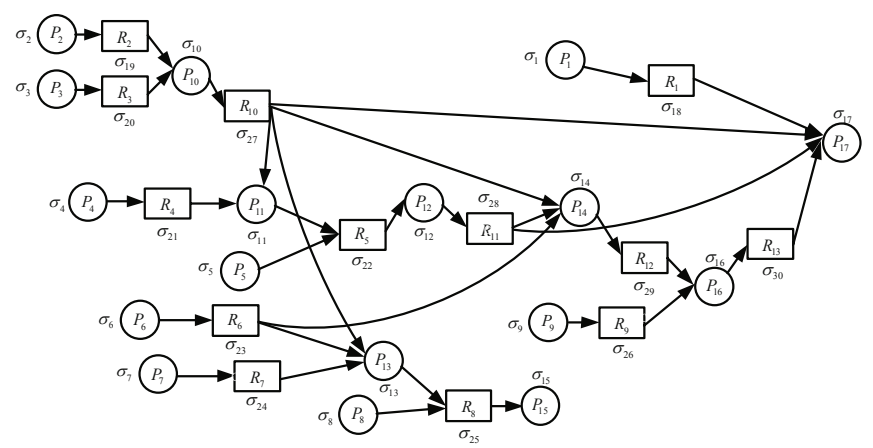

Fig. 4. A fault diagnosis model based on rFRSN P systems for the power supply systems

Rule 10: IF $P_{10}$ THEN $P_{11}$ AND $P_{13}$ AND $P_{14}$ AND $P_{17}(\mathrm{CF}=0.85)$

Rule 11: IF $P_{12}$ THEN $P_{14}$ AND $P_{17}(\mathrm{CF}=0.8)$

Rule 12: IF $P_{14}$ THEN $P_{16}(\mathrm{CF}=0.95)$

Rule 13: IF $P_{16}$ THEN $P_{17}(\mathrm{CF}=0.9)$

\subsection{A Fault Diagnosis Model for the Traction and Braking Systems}

Fuzzy production rules (Rules 1 to 10), describing the relationships between breakdown signals detected and candidate faulty sections, for traction and braking systems of electric locomotives are described as follows, where CF represents the certainty (confidence) factor of a rule, $P_{1}, \ldots, P_{16}$ are propositions whose meanings are shown in Table 3 . According to these fuzzy production rules, a fault diagnosis model based on rFRSN P systems for traction and braking systems $\Pi_{3}=\left(O, \sigma_{1}, \ldots, \sigma_{26}\right.$, syn, in, out $)$ is built, as shown in Fig. 5, where:

(1) $O=\{a\}$ is the singleton alphabet ( $a$ is called spike);

(2) $\sigma_{1}, \ldots, \sigma_{16}$ are proposition neurons associated with propositions $P_{1}, \ldots, P_{16}$, respectively;

(3) $\sigma_{17}, \sigma_{18}, \sigma_{23}, \ldots, \sigma_{26}$ are $G E N E R A L$ rule neurons associated with fuzzy production rules $R_{1}, R_{2}, R_{7}, \ldots, R_{10}$, respectively; $\sigma_{20}, \ldots, \sigma_{22}$ are $O R$ rule neurons associated with fuzzy production rules $R_{4}, \ldots, R_{6}$, respectively;

(4) $\operatorname{syn}=\{(1,17),(2,18),(3,19),(4,19),(5,19),(6,20),(7,20),(8,21),(9,22)$, $(10,23),(11,22),(12,24),(13,25),(14,26),(15,21),(17,16),(18,16),(19,13)$, $(20,14),(21,16),(22,16),(23,16),(24,16),(25,15),(26,16)\}$; 
(5) in $=\left\{\sigma_{1}, \ldots, \sigma_{12}\right\}$, out $=\left\{\sigma_{16}\right\}$.

Rule 1: IF $P_{1}$ THEN $P_{16}(\mathrm{CF}=0.85)$

Rule 2: IF $P_{2}$ THEN $P_{16}(\mathrm{CF}=0.8)$

Rule 3: IF $P_{3}$ OR $P_{4}$ OR $P_{5}$ THEN $P_{13}(\mathrm{CF}=0.9)$

Rule 4: IF $P_{6}$ OR $P_{7}$ THEN $P_{14}(\mathrm{CF}=0.95)$

Rule 5: IF $P_{8}$ OR $P_{15}$ THEN $P_{16}(\mathrm{CF}=0.9)$

Rule 6: IF $P_{9}$ OR $P_{11}$ THEN $P_{16}(\mathrm{CF}=0.8)$

Rule 7: IF $P_{10}$ THEN $P_{16}(\mathrm{CF}=0.7)$

Rule 8: IF $P_{12}$ THEN $P_{16}(\mathrm{CF}=0.85)$

Rule 9: IF $P_{13}$ THEN $P_{15}(\mathrm{CF}=0.95)$

Rule 10: IF $P_{14}$ THEN $P_{16}(\mathrm{CF}=0.75)$

Table 3. Meaning of each proposition in fuzzy production rules for traction and braking systems

\begin{tabular}{|l|c|c|c|}
\hline$P_{1}$ & DC110V breakdown & $P_{9}$ & main protective relay breakdown \\
\hline$P_{2}$ & control source converter plate breakdown & $P_{10}$ & traction power controller breakdown \\
\hline$P_{3}$ & U-phase current sensor breakdown & $P_{11}$ & A/D breakdown \\
\hline$P_{4}$ & W-phase current sensor breakdown & $P_{12}$ & $25 / 5 \mathrm{~V}$ breakdown \\
\hline$P_{5}$ & V-phase current sensor breakdown & $P_{13}$ & more than one among $P_{3}, P_{4}$ and $P_{5}$ happen \\
\hline$P_{6}$ & first linear electromotor group breakdown & $P_{14}$ & linear electromotor inoperation \\
\hline$P_{7}$ & second linear electromotor group breakdown & $P_{15}$ & phase current sensor inoperation \\
\hline$P_{8}$ & main traction invertor breakdown & $P_{16}$ & traction and braking system inoperation \\
\hline
\end{tabular}

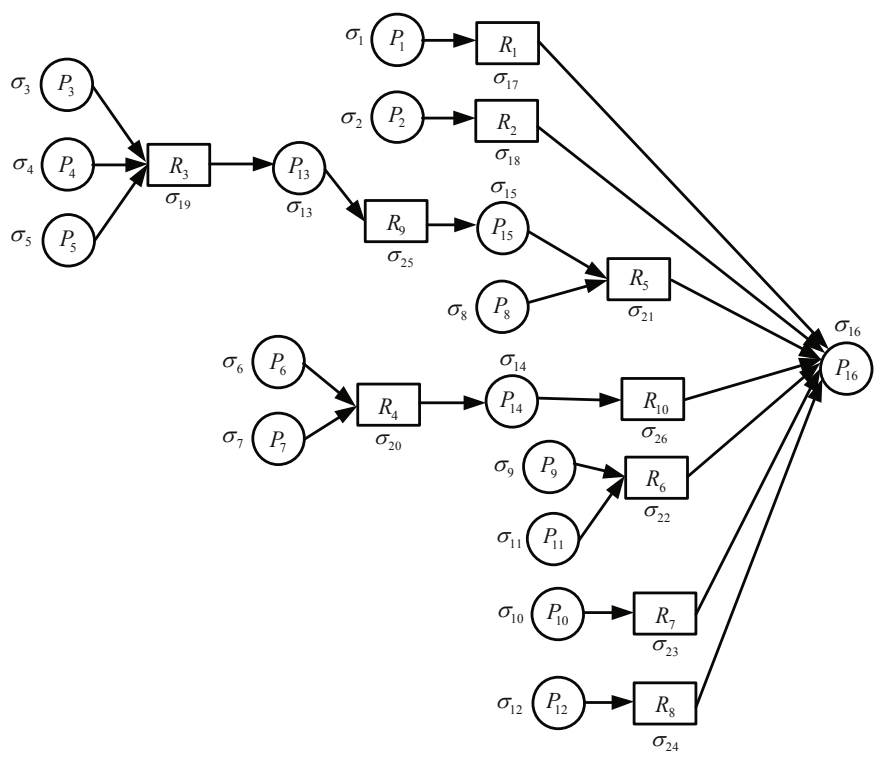

Fig. 5. A fault diagnosis model based on rFRSN P systems for the traction and braking systems 


\subsection{A Fault Diagnosis Model for the Electric Locomotive Systems}

From Fig. 3 to Fig. 5, we know that if there is no current in pantograph or traction transformers breakdown or pulling motors inoperation or contactors breakdown, then the main circuit system of electric locomotive systems has faults; if DC750V input breakdown or fan inoperation or main traction invertor breakdown or DC110V breakdown, then the power supply system of electric locomotive systems has faults; if DC750V input breakdown or fan inoperation or main traction invertor breakdown or DC110V breakdown, then the power supply system of electric locomotive systems has faults; if the main traction invertor breakdown or DC110V breakdown or control source converter plate breakdown or main protective relay breakdown or traction power controller breakdown or $\mathrm{A} / \mathrm{D}$ breakdown or $25 / 5 \mathrm{~V}$ breakdown or linear electromotor inoperation or phase current sensor inoperation, then the traction and braking system of electric locomotive systems has faults.

Table 4. Meaning of each proposition in fuzzy production rules for electric locomotive systems

\begin{tabular}{|c|c|c|c|}
\hline$P_{1}$ & no current in pantograph & $P_{10}$ & main protective relay breakdown \\
\hline$P_{2}$ & traction transformer breakdown & $P_{11}$ & traction power controller breakdown \\
\hline$P_{3}$ & pulling motor inoperation & $P_{12}$ & A/D breakdown \\
\hline$P_{4}$ & contactor breakdown & $P_{13}$ & $25 / 5 \mathrm{~V}$ breakdown \\
\hline$P_{5}$ & DC750V input breakdown & $P_{14}$ & linear electromotor inoperation \\
\hline$P_{6}$ & fan inoperation & $P_{15}$ & phase current sensor inoperation \\
\hline$P_{7}$ & main traction invertor breakdown & $P_{16}$ & main circuit system has faults \\
\hline$P_{8}$ & DC110V breakdown & $P_{17}$ & power supply system has faults \\
\hline$P_{9}$ & control source converter plate breakdown & $P_{18}$ & traction and braking system has faults \\
\hline$P_{19}$ & \multicolumn{3}{|c}{ electric locomotive systems has faults } \\
\hline
\end{tabular}

For an electric locomotive system, if one or more than one of its subsystems (main circuit systems, power supply systems, and traction and braking systems) have faults, then this electric locomotive system has faults. According to the analysis, fuzzy production rules (Rules 1 to 4) for electric locomotive systems are described as follows, where CF represents the certainty (confidence) factor of a rule, $P_{1}, \ldots, P_{19}$ are propositions whose meanings are shown in Table 4 . According to these fuzzy production rules, a fault diagnosis model based on rFRSN $\mathrm{P}$ systems for electric locomotive systems $\Pi_{4}=\left(O, \sigma_{1}, \ldots, \sigma_{23}\right.$, syn, in, out $)$ is built, as shown in Fig. 6, where:

(1) $O=\{a\}$ is the singleton alphabet ( $a$ is called spike);

(2) $\sigma_{1}, \ldots, \sigma_{19}$ are proposition neurons associated with propositions $P_{1}, \ldots, P_{19}$, respectively;

(3) $\sigma_{20}, \ldots, \sigma_{23}$ are $O R$ rule neurons associated with fuzzy production rules $R_{1}, \ldots, R_{4}$, respectively;

(4) syn $=\{(1,20),(2,20),(3,20),(4,20),(5,21),(6,21),(7,21),(7,22),(8,21),(8,22)$, $(9,22),(10,22),(11,22),(12,22),(13,22),(14,22),(15,22),(16,23),(17,23)$, $(18,23),(20,16),(21,17),(22,18),(23,19)\}$;

(5) in $=\left\{\sigma_{1}, \ldots, \sigma_{15}\right\}$, out $=\left\{\sigma_{19}\right\}$. 


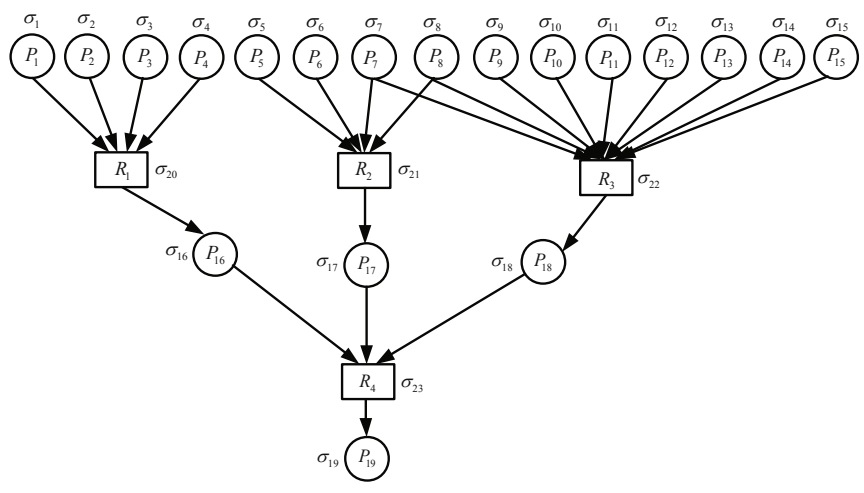

Fig. 6. A fault diagnosis model based on rFRSN P systems for the electric locomotive systems

Rule 1: IF $P_{1}$ OR $P_{2}$ OR $P_{3}$ OR $P_{4}$ THEN $P_{16}(\mathrm{CF}=0.95)$

Rule 2: IF $P_{5}$ OR $P_{6}$ OR $P_{7}$ OR $P_{8}$ THEN $P_{17}(\mathrm{CF}=0.95)$

Rule 3: IF $P_{7}$ OR $P_{8}$ OR $P_{9}$ OR $P_{10}$ OR $P_{11}$ OR $P_{12}$ OR $P_{13}$ OR $P_{14}$ OR

$P_{15}$ THEN $P_{18}(\mathrm{CF}=0.95)$

Rule 4: IF $P_{16}$ OR $P_{17}$ OR $P_{18}$ THEN $P_{19}(\mathrm{CF}=0.98)$

\section{Conclusions}

In this study, rFRSN P systems are applied in fault diagnosis of electric locomotive systems. This study focuses on describing relationships among breakdown signals, faulty sections, faulty subsystems and faulty electric locomotive systems in the form of fuzzy production rules by using syntactical ingredients provided by rFRSN $\mathrm{P}$ systems. It proposes fault diagnosis models based on rFRSN P systems for SS4 electric locomotive systems. These models can visually and formally describe relationships among breakdown signals detected and candidate faulty sections or faulty systems. This work is an important theoretical basis for proposing a novel bio-inspired method for fault diagnosis of electric locomotive systems by using rFRSN P systems. To test and verify the practical implementation and scalability of the proposed method, our future work includes the development of diagnosis algorithms for the models proposed in this paper and model reduction algorithms for the models used in specific cases. Experiments with a tool we aim to develop will prove the effectiveness of these algorithms and the approach presented in this paper.

Acknowledgments. This work is supported by the National Natural Science Foundation of China $(61170016,61373047,61170030)$, the Program for New Century Excellent Talents in University (NCET-11-0715) and SWJTU supported project (SWJTU12CX008). The last author acknowledges the support of the project TIN 20123734 of the Ministerio de Economía y Competitividad of Spain. 


\section{References}

1. Păun, Gh.: Computing with membranes. J. Comput. Syst. Sci. 61(1), 108-143 (2000)

2. Ionescu, M., Păun, Gh., Yokomori, T.: Spiking neural P systems. Fund. Inform. 71(2-3), 279-308 (2006)

3. Păun, Gh., Pérez-Jiménez, M.J., Rozenberg, G.: Spike train in spiking neural P systems. Int. J. Found. Comput. Sci. 17(4), 975-1002 (2006)

4. Chen, H., Ishdorj, T.O., Păun, Gh., Pérez-Jiménez, M.J.: Handling languages with spiking neural P systems with extended rules. Rom. J. Inf. Sci. Tech. 9(3), 151-162 (2006)

5. Freund, R., Ionescu, M., Oswald, M.: Extended spiking neural P systems with decaying spikes and/or total spiking. Int. J. Found. Comput. Sci. 19(5), 1223-1234 (2008)

6. Cavaliere, M., Ibarra, O.H., Păun, Gh., Egecioglu, O., Ionescu, M., Woodworth, S.: Asynchronous spiking neural P systems. Theor. Comput. Sci. 410(24-25), 2352-2364 (2009)

7. Pan, L.Q., Păun, Gh.: Spiking neural P systems: an improved normal form. Theor. Comput. Sci. 411(6), 906-918 (2010)

8. Pan, L.Q., Zeng, X.X.: Small universal spiking neural P systems working in exhaustive mode. IEEE Trans. on Nanobiosci. 10(2), 99-105 (2011)

9. Metta, V.P., Krithivasan, K., Garg, D.: Spiking neural P systems with anti-spikes as transducers. Rom. J. Inf. Sci. Tech. 14(1), 20-30 (2011)

10. Ionescu, M., Păun, Gh., Pérez-Jiménez, M.J., Rodríguez-Patón, A.: Spiking neural P systems with several types of spikes. Int. J. Comput. Commun. 71(2-3), 648-656 (2011)

11. Zhang, X.Y., Luo, B., Fang, X.Y., Pan, L.Q.: Sequential spiking neural P systems with exhaustive use of rules. BioSystems 108, 52-62 (2012)

12. Cabarle, F.C., Adorna, H.N., Martínez-del-Amor, M.A., Pérez-Jiménez, M.J.: Improving GPU simulations of spiking neural P systems. Rom. J. Inf. Sci. Tech. 15(1), 5-20 (2012)

13. Cabarle, F.G.C., Adorna, H.N.: On structures and behaviors of spiking neural P systems and Petri nets. In: Csuhaj-Varjú, E., Gheorghe, M., Rozenberg, G., Salomaa, A., Vaszil, Gy. (eds.) CMC 2012. LNCS, vol. 7762, pp. 145-160. Springer, Heidelberg (2013)

14. Song, T., Pan, L.Q., Păun, Gh.: Asynchronous spiking neural P systems with local synchronization. Inform. Sciences 219, 197-207 (2013)

15. Jiang, K.Q., Song, T., Pan, L.Q.: Universality of sequential spiking neural P systems based on minimum spike number. Theor. Comput. Sci. 499, 88-97 (2013)

16. Zhang, G.X., Rong, H.N., Neri, F., Pérez-Jiménez, M.J.: An optimization spiking neural $\mathrm{P}$ system for approximately solving combinatorial optimization problems. Int. J. Neural Syst. 24(5), 1-15 (2014)

17. Wang, J., Shi, P., Peng, H., Pérez-Jiménez, M.J., Wang, T.: Weighted fuzzy spiking neural P system. IEEE Trans. Fuzzy Syst. 21(2), 209-220 (2013)

18. Peng, H., Wang, J., Pérez-Jiménez, M.J., Wang, H., Shao, J., Wang, T.: Fuzzy reasoning spiking neural $\mathrm{P}$ system for fault diagnosis. Inform. Sciences 235, 106-116 (2013)

19. Xiong, G.J., Shi, D.Y., Zhu, L., Duan, X.Z.: A new approach to fault diagnosis of power systems using fuzzy reasoning spiking neural P systems. Math. Probl. Eng. (2013). http://dx.doi.org/10.1155/2013/815352 
20. Wang, T., Zhang, G.X., Rong, H.N., Pérez-Jiménez, M.J.: Application of fuzzy reasoning spiking neural $\mathrm{P}$ systems to fault diagnosis. Int. J. Comput. Commun. 9(6), 786-799 (2014)

21. Tu, M., Wang, J., Peng, H., Shi, P.: Application of adaptive fuzzy spiking neural $\mathrm{P}$ systems in fault diagnosis of power systems. Chinese J. Electron. 23(1), 87-92 (2014)

22. Zhang, C.Y.: Research on fault diagnosis method of electric locomotive systems based on Petri net (M.S Degree Thesis). Central South University, Changsha, China (2010)

23. Zhang, Y.S., Zhu, L.J.: Shaoshan4 Locomotive. Chinese Railway Publishing House, Beijing (2001) 